\title{
Scale and scope matter when explaining varying patterns of community diversity in riverine metacommunities
}

\author{
Mathew Seymour ${ }^{\mathrm{a}, \mathrm{b},{ }^{*}}$, Kristy Deiner ${ }^{\mathrm{a}}$, Florian Altermatt ${ }^{\mathrm{a}, \mathrm{c}}$ \\ ${ }^{a}$ Eawag, Swiss Federal Institute of Aquatic Science and Technology, Department of Aquatic \\ Ecology, Überlandstrasse 133, 8600 Dübendorf, Switzerland. \\ ${ }^{\mathrm{b}}$ Southern Insect Management Research Unit, USDA-ARS, Stoneville, MS 38776. \\ ${ }^{\mathrm{c}}$ Institute of Evolutionary Biology and Environmental Studies, University of Zurich \\ Winterthurerstr. 190, CH-8057 Zürich, Switzerland. \\ *Corresponding author. Tel.: +1 (662) 686-5267; fax: +1 (662) 686-5421. \\ E-mail address: Mat.Seymour@gmail.com.
}




\section{Abstract}

Large-scale species and genetic metacommunity patterns are influenced by variation in environmental factors and distance between communities, according to previous studies. However, these studies often used different measures to assess patterns of metacommunity diversity, distances between communities and grain sizes at which environmental variables are measured. This hinders interpretations and generalizations of the underlying process that drive metacommunity diversity. We applied a synthetic and multi-analytical approach to identify general factors structuring the diversity of a large riverine metacommunity. Using complementing approaches we analysed how distance, measured as Euclidean or topological distance, and environmental factors, assessed at different grain sizes, influenced different measures of metacommunity diversity (species richness, functional richness and phylogenetic diversity) of mayfly, stonefly and caddisfly species in a large river network (river Rhine, Switzerland). We found the amount of explained variation in species diversity was generally unaffected by grain size, but improved with the use of topological distance, compared to Euclidean distance. Variation in functional diversity was best explained by environmental factors at small grain sizes and topological distance. Variation in phylogenetic diversity was best explained when environmental variables were assessed at larger grain sizes and Euclidean distance was used. Overall, our results indicate that processes structuring metacommunity diversity may differ at the species, functional or phylogenetic level of the community, as recently postulated in the metacommunity-phylogenetics approach. While such differences may hinder comparisons across studies using different methodologies, it offers opportunities to disentangle the structuring factors within metacommunities by applying multiple analytical approaches to the same dataset. 


\section{Zusammenfassung}

Umweltfaktoren und räumliche Distanz beeinflussen die Zusammensetzung und Diversität von biologischen Gemeinschaften auf der Ebene von Arten und Genen. Bisherige Studien, welche Diversitätsmuster in sogenannten "Metacommunities” untersuchten, verwendeten jedoch oftmals unterschiedliche Masse an Diversität, unterschiedliche räumliche Distanzmasse zwischen den Artgemeinschaften, und unterschiedliche räumliche Skalierungen der Umweltvariablen. Diese methodische Heterogenität erschwert oder verhindert die Interpretation und Generalisierung der Prozesse, welchen die Diversitätsmuster in Metacommunities unterliegen. In unserer Studie nutzten wir einen vereinheitlichenden Ansatz um Diversitätsmuster und deren unterliegenden Faktoren in großräumigen Flussnetzwerksystemen zu analysieren. Wir verwendeten komplementäre Methoden, um den Einfluss von räumlicher Struktur (als euklidische und topologische Distanz gemessen) und verschiedener Umweltvariablen (gemessen auf unterschiedlichen Skalen) auf die Diversität (Artreichtum, funktionelle Vielfalt und genetische Vielfalt) von Eintags-, Stein- und Köcherfliegen-Gemeinschaften in einem großen Flussnetzwerk (gesamtes Einzugsgebiet des Rheins in der Schweiz) zu untersuchen. Wir fanden, dass der Anteil der erklärten Varianz der Zusammensetzung der Artgemeinschaften grundsätzlich unabhängig von der Skalierung der Umweltvariablen war, sich jedoch verbesserte wenn wir die räumliche Struktur mit topologischer anstatt euklidischer Distanz beschrieben. Im Gegensatz dazu wurde die Varianz der funktionellen Diversität am besten durch kleinräumig erfasste Umweltvariablen und topologische Distanz erklärt. Die Varianz der phylogenetischen Diversität wurde am besten durch großräumig erfasste Umweltvariablen und euklidische Distanz beschrieben. Generell zeigen unsere Resultate, dass unterschiedliche Prozesse für die Strukturierung von Metacommunities auf der Ebene von Arten, funktioneller und phylogenetischer Diversität verantwortlich sind, wie dies auch im "Metacommunity-Phylogenetics" Ansatz postuliert wurde. Diese Unterschiede erschweren Vergleiche zwischen Studien mit unterschiedlichen 
Ansätzen. Gleichzeitig können dadurch die wichtigsten strukturierenden Faktoren innerhalb desselben Datensatzes ermittelt werden.

Keywords: macroinvertebrates, freshwater, variance partitioning, phylogenetic, functional, metacommunity phylogenetics

\section{Introduction}

Determining the relative importance of environmental and spatial factors (henceforth referred to as "distance") shaping community diversity is a fundamental pursuit of ecology and biogeography. Interest in the combined effects of environmental factors and distance on community diversity has been fuelled by metacommunity and metacommunity-phylogenetic research, since many natural metacommunities have an inherent link between environment and distance (Borcard, Legendre, \& Drapeau, 1992; Holyoak, Leibold, \& Holt, 2005; Leibold et al., 2004; Leibold, Economo, \& Peres-Neto, 2010). This is especially true for riverine metacommunities, which have a unique hierarchical structure that influences species dispersal patterns and environmental variation (Altermatt, 2013; Altermatt et al., 2014; RodriguezIturbe \& Rinaldo, 1997; Vannote, Minshall, Cummins, Sedell, \& Cushing, 1980). Many different approaches (e.g., different response and explanatory variables) have been used to assess the combined influence of distance and environmental factors on riverine metacommunities, resulting in a range of empirical findings (e.g., Altermatt, Seymour, \& Martinez, 2013; Astorga et al., 2012; Heino et al., 2015; Liu, Soininen, Han, \& Declerck, 2013). However, the wide range of approaches and selection of explanatory and response variables in previous studies has hindered across-study comparisons, thus limiting efforts to get a synthetic understanding of the significance and generality of what drives community 
diversity across river systems worldwide. Additionally, few studies have systematically assessed the influence of using different explanatory variables measured at different scales on multiple measures of metacommunity diversity (i.e., species richness, functional richness and phylogenetic diversity).

Generally, one of three response variables are used to measure metacommunity diversity; namely species richness, functional richness or phylogenetic diversity (Fig. 1). Species richness is the most common method (Rosenzweig, 1995) and is frequently related to environmental and distance factors (Rodrigues \& Gaston, 2002). Alternatively, functional richness, which integrates life-history and trait data, may provide a better measure of metacommunity diversity, especially where changing food availability alters the trophic structure (Vannote et al., 1980). Finally, phylogenetic diversity, which reflects a measure of past evolutionary dynamics and diversification, might capture relationships due to processes such as convergence or cryptic species (e.g., Forest et al., 2007), which are overlooked by using species and functional richness. Overall, these three different measures of metacommunity diversity address different aspects of metacommunity diversity and are likely related to different mechanisms structuring metacommunities.

The strong effect of environmental factors on species, functional and phylogenetic metacommunity diversity is often associated with environmental filtering (Weiher \& Keddy, 1999) and is often related to variation in climate and temperature along environmental gradients (Rosenzweig, 1995; Urban, 2004). Explanatory environmental factors include, among others, measures of climate (e.g., temperature), water chemistry, land-use (i.e., anthropogenic influence) and elevation. Often, these environmental factors are assessed at the local-scale (e.g., Astorga et al., 2012; Liu et al., 2013) or at a fixed spatial scale around a site (herein referred to as grain size). The grain size at which environmental measurements are taken may greatly influence the findings of a study, due to differences between local and 
global environmental effects on community diversity (e.g., Alahuhta \& Heino, 2013;

Münkemüller et al., 2014; Vaughan et al., 2009). Additionally, the grain size at which one species is affected may differ from other species due to species-specific differences in environmental tolerance or dispersal ability (Turner, Gardner, \& O’Neill, 2001; Wiens, 1989).

While environmental factors greatly influence community diversity, recent empirical studies also show distance between communities, independent of environmental factors, alters the spatial and temporal dynamics of metacommunity diversity by modifying dispersal patterns and subsequent species interactions (e.g., Carrara, Altermatt, Rodriguez-Iturbe, \& Rinaldo, 2012; Muneepeerakul et al., 2008; Seymour, Fronhofer, \& Altermatt, 2015). In the past, distance between communities has often been measured as Euclidean distance (Blanchet, Legendre, \& Borcard, 2008b). More recent work, however, suggests that topological distance may better reflect dispersal distance for species that are confined to or primarily disperse along the river network (Altermatt, 2013; Seymour, Räsänen, Holderegger, \& Kristjánsson, 2013; Turner et al., 2001).

The goal of our study was to identify what effect environment, measured at different grain sizes, and spatial connectivity among communities have on structuring riverine metacommunities when using different metacommunity diversity measures. We used data from a large biodiversity-monitoring program, which monitored mayfly, stonefly and caddisfly communities across a large drainage basin in Switzerland, Central Europe. We asked three main questions: First, how do metacommunity measures of species, functional and phylogenetic diversity relate to different environmental factors and distance in riverine metacommunities? Second, what are the effects of using different grain sizes to describe variation in environmental factors and different distance measures in explaining metacommunity diversity? Finally, does the use of multiple levels of explanatory and response variables allow us to disentangle the processes, acting at different scales, which are 
structuring riverine metacommunities? These three questions aim at understanding general assembly processes of natural communities at landscape scales.

\section{Materials and methods}

\section{Study system}

Data on the distribution and diversity of all mayfly, stonefly and caddisfly species (order Ephemeroptera, Plecoptera, and Trichoptera; abbreviated as EPT) were sampled at 217 sites within the Rhine drainage (covering $28,054 \mathrm{~km}^{2}$ ) in Switzerland, Central Europe. The data were systematically collected within the Swiss Biodiversity Monitoring Program (BDM Coordination Office, 2009), with sampling occurring once for each site between 2009 and 2012. Sites sampled from each year were a random subset of the sites sampled during the entire survey, in order to avoid spatio-temporal autocorrelation between different years (BDM Coordination Office, 2009). General sampling methods were used (for details see Altermatt et al. 2013). In short, sampling sites were randomly selected on a systematic grid across Switzerland (BDM Coordination Office, 2009). In order to maximise the detection of macroinvertebrates, sampling date was adjusted to elevation. For low elevation sites, sampling occurred in March to April, while at high elevation sites sampling occurred in June to July (for a detailed scheme of the sampling dates with respect to elevation, see Stucki, 2010). This sampling regime has been previously tested and verified to be the best for reflecting local macroinvertebrate diversity (BDM Coordination Office, 2009; Stucki, 2010). All EPT were sampled using kick-nets and following methods described in Altermatt et al. (2013). Trained field biologists collected, identified and preserved individuals from all sites, using standardized methods (BDM Coordination Office, 2009). All individuals were, when possible, identified to the taxonomic species level by specialists using previously established 
nomenclature and identification keys. Few species could not be separated at the larval stage and were placed in pre-defined species complexes, which were treated as single species in this study. Most of these species complexes consist of sister-species, where only one of the species is actually occurring in our study area (and the sister species occurs south of the Alps in Switzerland); thus, the use of sister species did not bias our analyses. Details regarding the definition of the species complexes are available in Stucki (2010) and BDM Coordination Office (2009) and supplements therein. Species within each complex are functionally and taxonomically highly similar and are expected to be phylogenetically related when compared to other species groups (see also Moog, 2002)

\section{Metacommunity diversity measures}

Community diversity of EPT was assessed using three different methods: species richness, functional richness and phylogenetic diversity. Community abundances for each method were structured as traditional community matrices (Borcard, Gillet, \& Legendre, 2011) with each column representing a unique group (i.e., species, functional or phylogenetic group), and each row representing a unique sampling site. The cells were then filled with the appropriate community measure, detailed below, for the given group (column) at the given site (row). These three matrices were used as response variables in the ensuing variance partitioning analyses.

Species richness was calculated as the number of unique species per site. Abundances of each species per site were formatted as a species matrix (site by species matrix) and standardized using a Hellinger transformation. Transformation of the species richness matrix, and subsequently described matrices, is required to meet the assumption that vectors are standardized prior to multivariate analysis, which allows comparison of the vectors (e.g., variance partitioning) (Borcard et al., 1992; Legendre \& Legendre, 2012). Functional richness was calculated as the number of unique functional groups per sites, following the designation 
of functional groups in Moog (2002). These groups reflect the species' trophic function, divided into 8 categories including; grazer/scrapers, xylophagous, shredders, gather/collectors, active filter feeders, passive filter feeders, predators and other. We provide the details of our functional groupings in Appendix A (Table A.1). As with species abundances we formatted the functional group abundances as a site by functional group matrix, which was standardized using a Hellinger transformation.

Phylogenetic diversity was calculated using the following method. Cytochrome-c Oxidase I (COI) mitochondrial sequences and 18s ribosomal sequences were collected from collaborative sources and GenBank, by searching for all entries that matched the genera used in our study. We aligned COI and 18s sequences, separately, after checking for general quality standards using ClusterW implemented in Mega5 (Thompson, Higgins, \& Gibson, 1994). We then calculated Tamura-Nei pairwise genetic distance correction for COI and $18 \mathrm{~s}$ alignments separately and concatenated the two distance measures (Schierwater et al., 2009). This gave us a single pairwise-distance matrix for phylogenetic variation across all genera for each order of EPT. Pairwise-distances between genera were then used to create a weighted phylogenetic diversity matrix (phylogenetic groupings by site) (Leibold et al., 2010), whereby the phylogenetic diversity of each genus at a given site was measured as the sum of the phylogenetic distances from all other genera at a given site and then standardized against the total phylogenetic distance across all sites (Leibold et al., 2010). A more detailed description of the phylogenetic diversity measure calculation and a molecular tree visualization are provided in Appendix A.

Generally, one needs to ensure the use of appropriate standardization methods, as they may impact the results (Blanchet, Legendre, Bergeron, \& He, 2014; Legendre \& Cáceres, 2013; Warton, Wright, \& Wang, 2012). We used metric based standardizations following established methods; including Hellinger transformation for the above mentioned species and 
functional matrices (Legendre \& Legendre, 2012; Rao, 1995) and standardization against total phylogenetic distance for phylogenetic diversity matrix (Leibold et al., 2010), as recommended for use in ordination analyses, including variance partitioning, which is used below.

\section{Environmental variables}

Environmental variables were selected based on ecological relevance and their past use in studies on community diversity of aquatic insects in river systems (e.g., Heino, 2005). These environmental factors not only reflect the type of variables used in many studies on aquatic invertebrates in river systems, but also describe water-quality and abiotic conditions that are directly linked to species life-cycles and habitat requirements and are hypothesized to drive metacommunity diversity patterns (e.g., Heino, 2005; Heino et al., 2015). All environmental variables were taken from previously catalogued geographic information system (GIS) data. We included the following environmental factors: elevation (m a.s.l.), mean annual temperature and precipitation, \%calcite cover and \%land-use type cover (Fig. B.2). Temperature and precipitation data were measured as annual means at the sites using data from the Swiss Federal Office of meteorology and Climatology (Begert, Schlegel, \& Kirchhofer, 2005). Percent calcite cover data were provided by the Swiss Federal Statistical Office (BFS 2001). Land-use data; including percent coverage of agriculture, settlement, wooded areas, meadows, other types, were collected using the Swiss Federal Statistical Office following the CORINE (Co-ordination of Information on the Environment) program (SFSO, 1998).

Calcite and land-use type environmental factors were measured at seven grain sizes for the individual sub-catchments, namely at $500 \mathrm{~m}, 1 \mathrm{~km}, 5 \mathrm{~km}, 10 \mathrm{~km}, 50 \mathrm{~km}, 100 \mathrm{~km}$ and 1000 km grain size buffers (see Appendix A: Fig. A.3). This range reflects a continuum of very local to regional scales. Sub-catchments used for each grain size at each sampling site were 
first created using ArcGIS 10 (ESRI, 2011) to compile previously defined sub-catchments from the Swiss Federal Office of the Environment (BAFU 2012). We then clipped the desired grain size distance upstream from the sampling site. When the grain size distance extended beyond the catchment extent, we used only the catchment area to summarize land-use and calcite cover data (see Appendix A: Fig. A.3). These sub-catchments were then used to summarize the land-use and calcite cover data for each sampling site by taking the total area for each land-use type and calcite cover relative to catchment size. Grain sizes did not change how the community diversities or distance matrices were calculated or assessed, as the latter are always based on the sampling site-specific data (i.e., they reflect the green points in Fig. 2, while the environmental variables correspond to the yellow areas).

\section{Distance descriptors}

Pairwise-distances between sites were measured as Euclidean (straight-line) distance and as topological distance (along the river network) using the network analysis toolkit in the program ArcGIS 10. Topological and Euclidean distance correlate with each other (see Fig. 5 in Altermatt, 2013), however, topological distance can be up to 10 times larger for a given Euclidian distance between two points. We decomposed the pairwise distances between sites using principal coordinates of the neighbourhood matrix (PCNM), using the minimum distance required for the given connected network as the threshold, in the package vegan (Borcard et al., 2011; Oksanen et al., 2009) using the program R version 3.0.0 (R Development Core Team, 2015). PCNM is a method developed to decompose a set of spatial distances into a matrix of orthogonal variables (Legendre \& Legendre, 2012), and is part of a family of algorithms known as Moran's eigenvector maps (Dray, Legendre, \& Peres-Neto, 2006). This method has benefits over traditional distance descriptor methods (e.g., polynomial), as it produces independent spatial variables, representing a wider range of spatial scales to compare similarities (Borcard et al., 2011; Dray et al., 2006). Compared to 
other taxa, for example such as passively dispersed diatoms (e.g., Liu et al., 2013), EPT are generally thought to have little or no dispersal bias into up- or downstream directions, as passive downstream drift of larvae is compensated by upstream flight by adults. As there were no good prior assumptions regarding directionality, we used undirected dispersal as the most conservative and most parsimonious approach.

\section{Analysis}

We used variance partitioning to independently assess the relationship between each community diversity measure using the species, functional and phylogenetic matrices, described previously, as the response variables, and each combination of environmental and distance components (PCNMs), previously described, as explanatory variables (Borcard et al., 2011). Variance partitioning is a multivariate approach that partitions the unique and shared variation of two or more sets (e.g., matrices) of explanatory variables, on a single matrix of response variables. To maintain parsimony, prior to the variance partition we assessed the significance of the explanatory variables on the response variable using redundancy analyses (RDA) and the following workflow (Borcard et al., 2011). First, we assessed if the global model (i.e., all variables included) was statistically significant using permutation tests with 1000 permutations. When the global model was significant we performed a forward selection of the environmental and PCNM variables for each analysis to avoid Type I errors, following the methods of Blanchet et al. (2008a). We then performed the variance partition analysis using the response matrix in relation to the forward-selected explanatory matrices (i.e., environmental and PCNMs). The partitioned variation for each metacommunity diversity measures (species, functional or phylogenetic) was then explained in three components of variation (Fig. 1). First, a component explained by the set of environmental variables, which is independent of metacommunity connectivity. Second, a component explained by metacommunity connectivity, which is independent of environmental variation. Third, a 
component explained by environmental variation and distance. Partitioned fractions were adjusted based on the number of predictor variables, following Peres-Neto et al. (2006). Finally, we tested the significance of the environmental and distance components of explained variation (i.e., the testable fractions of variation, which can be tested using the regression method) using a permutation test with 1000 permutations for correspondence analysis (CCorA) (Legendre \& Legendre, 2012).

\section{Results}

\section{Metacommunity diversity}

Species richness per site ranged from 1 to 35 species, with an average of 16 species (Fig. 2A). For a list of all species observed and the number of sites at which they occurred, see Appendix A (Table A.4). Low numbers of species (1 to 9 species) were found at high elevation (headwater) sites (1,500 to 2,270 $\mathrm{m}$ a.s.1.), and low elevation sites ( $\sim 500 \mathrm{~m}$ a.s.1.), where agriculture and settlements are the predominant land-use types. High numbers $(>25$ species) were found at mid-elevation sites ( $~ 850 \mathrm{~m}$ a.s.1.), which were dominated by meadows and wooded areas. Functional richness per site ranged from 2 to 8 functional groups per site (Fig. 2B), with an average of 5 functional groups. Communities with few functional groups (2 to 3 groups) occurred either at very high ( $>2,000 \mathrm{~m}$ a.s.1.) or low (<500 $\mathrm{m}$ a.s.l.) elevation and were usually consisted of grazer/scrapers or gatherer/collector communities. High functional richness was found across low to mid-elevation sites (400 to $900 \mathrm{~m}$ a.s.l.). Phylogenetic diversity per site ranged from $0.5 \%$ to $37.5 \%$ variation compared to the total phylogenetic diversity observed across all sites (Fig. 2C). Many of the sites had low phylogenetic diversity, indicating high similarity among sites, ranging from 0.5 to $5 \%$. These were primarily at low elevation sites (<500 $\mathrm{m}$ a.s.1.), with a few low phylogenetic diversity sites also occurring at mid to high elevations (1,000 to 2,500 m a.s.l.). Greater phylogenetic diversity (>20\%) was found primarily at mid-elevation sites (600 to $900 \mathrm{~m}$ a.s.1.). 
We found no significant correlations between variation in functional richness and species richness $\left(\mathrm{t}_{215}=0.037, \mathrm{p}\right.$-value $=0.971 ;$ Fig. $\left.3 \mathrm{~A}\right)$ or functional richness and phylogenetic diversity $\left(\mathrm{t}_{215}=0.277\right.$, $\mathrm{p}$-value $=0.782$; Fig. $\left.3 \mathrm{~B}\right)$. A significant positive correlation was found between variation in phylogenetic diversity and species richness using a glm (generalized linear model) with a Poisson distribution (cor $=0.815, \mathrm{z}_{215}=3.156$, p-value $<0.01$; Fig. $\left.3 \mathrm{C}\right)$.

\section{Variance partitioning}

Overall, environmental factors and distance measures explained $16 \%$ to $23 \%$ of the variation in metacommunity diversity. On average, variation in metacommunity diversity was mostly explained by each model's independent distance component $(9.4 \%, \mathrm{SD}=3.1)$ compared to the independent environmental component $(5.4 \%, \mathrm{SD}=1.4)$ or the non-independent environment $\cap$ distance component $(6.2 \%, \mathrm{SD}=3.0)$ (Fig. 4, Table C.1). The intersectionsign $(\cap)$ is used for the set of data containing the unique elements from both the environmental and distance components (non-independent). For all variance partitioning model results we found significant correlations between variation in species, functional and phylogenetic diversity and environment $(\mathrm{p}<0.01)$ and distance ( $\mathrm{p}$-value $<0.01$ to 0.02$)$ (see Appendix A: Table A.5).

Variation in species richness was explained mostly by environment $\cap$ distance $(10.3 \%, \mathrm{SD}=$ 1.1) compared to environmental factors $(6.3 \%, \mathrm{SD}=1.1)$ or distance $(5.3 \%, \mathrm{SD}=1.0)$. Functional richness variation was explained mostly by distance $(10.7 \%, \mathrm{SD}=1.0)$ compared to environmental factors $(4.2 \%, \mathrm{SD}=1.1)$ or environment $\cap$ distance $(3.8 \%, \mathrm{SD}=0.5)$. Phylogenetic diversity variation was explained mostly by distance $(12.2 \%, \mathrm{SD}=0.7)$, compared to environmental factors $(5.5 \%, \mathrm{SD}=1.1)$ or environment $\cap$ distance $(4.5 \%, \mathrm{SD}=$ 0.06). For significance values of these comparisons see Appendix A (Table A.5). 
The total explained variation in species richness remained consistent across models using different grain sizes (Fig. 4). Models derived from smaller grain sizes (500 $\mathrm{m}=19.4 \%, 1 \mathrm{~km}$ $=20.5 \%$ ) were marginally better at explaining variation in functional richness compared to models using larger grain sizes $(5 \mathrm{~km}=18.3 \%, 100 \mathrm{~km}=18.9 \%, 1000 \mathrm{~km}=17.7 \%)$. Conversely, models derived from larger grain sizes explained marginally more variation in phylogenetic diversity $(10 \mathrm{~km}=23.5 \%, 100 \mathrm{~km}=22.4 \%, 1000 \mathrm{~km}=22.4 \%)$ compared to smaller grain sizes $(500 \mathrm{~m}=20.3 \%, 1 \mathrm{~km}=21.2 \%)$. The change in explained variation for functional and phylogenetic diversity over different grain sizes were reflected in the environmental component of the models. Environmental factors explained greater variation in functional richness when models used smaller grain sizes $(500 \mathrm{~km}=4.9 \%, 1 \mathrm{~km}=6.0 \%)$, compared to those using larger grain sizes $(5 \mathrm{~km}=3.2 \%, 10 \mathrm{~km}=3.8 \%, 100 \mathrm{~km}=4.5 \%$, $1000 \mathrm{~km}=3.2 \%$ ). Comparatively, environmental factors explained greater variation in phylogenetic diversity when models used larger grain sizes $(5 \mathrm{~km}=6.5 \%, 10 \mathrm{~km}=6.7 \%, 100$ $\mathrm{km}=5.7 \%, 1000 \mathrm{~km}=5.7 \%)$ compared to those using smaller grain sizes $(500 \mathrm{~m}=3.6 \%, 1$ $\mathrm{km}=4.5 \%)$.

Distance models derived from topological distances better explained the variation in species $(22.9 \%, \mathrm{SD}=0.3$ versus $20.9 \%, \mathrm{SD}=0.4)$ and functional richness $(19.5 \%, \mathrm{SD}=1.2$ versus $18.0 \%, \mathrm{SD}=1.0)$, compared to models based on Euclidean distances. In contrast Euclideanbased distance models explained more variation in phylogenetic diversity $(21.8 \%, \mathrm{SD}=1.1$ versus $22.6 \%, \mathrm{SD}=1.3)$.

\section{Discussion}

Our findings highlight the importance of scale and scope of explanatory variables, such as variation in environmental factors and distance between communities, in explaining variation in community diversity, and their subsequent influence on conclusions regarding the processes shaping metacommunity diversity patterns. For example, the higher proportion of 
variance in species richness across sites (Fig. 2) explained by environmental factors suggests community assembly at a site is mostly driven by the local conditions (environmental filtering). Additionally, when measures of community diversity take into account the identity of the local species, captured by functional richness or phylogenetic diversity, this results in a higher amount of variance explained by distance measures, suggesting dispersal processes and colonization history as the likely mechanisms of community assembly. Importantly, while we found the total amount of explained variation of metacommunity diversity was surprisingly consistent among different combinations of explanatory and response variables (Fig. 1 and 4, see Appendix A: Table A.5), the amount of variation explained by environmental factors or distance surprisingly differed depending on the metacommunity diversity measure used (Fig. 2 and 4; see also Appendix A: Table A.5). Our findings call for a unifying approach (Cardoso, Rigal, Borges, \& Carvalho, 2014), integrating different sets of explanatory variables and response variables in order to understand and generalize processes and patterns in riverine metacommunities. We note that caution needs to be taken when directly interpreting variance partitioning results, which may be sensitive to the explanatory variables used and their spatial configuration (e.g., Gilbert \& Bennett, 2010; Smith \& Lundholm, 2010). However, variance partitioning results still provide a good starting point for assessing the potential explanatory variables influencing community diversity, which was one goal of our study.

Our results shed light on different processes shaping communities at different grain sizes. While the effect of grain size was marginal, and thus needs to be interpreted carefully, our observations may still point to responsible processes. Specifically, we found opposing patterns of proportion of explained variation among models using different grain sizes (Fig. 4). Variation in phylogenetic diversity was better explained by models using larger grain sizes (grain sizes $\geq 5 \mathrm{~km}$ ). This suggests that large-scale factors, such as refugia during glaciation in certain environments (e.g., lowlands not covered by ice) or even different phylogenetic 
diversification in certain environments (e.g., calcareous vs. non-calcareous sites) influence phylogenetic diversity (Eme, Malard, Konecny-Dupré, Lefébure, \& Douady, 2013; Weiss, Macher, Seefeldt, \& Leese, 2014). Conversely, variation in functional richness was better explained with models using smaller grain sizes $(\leq 1 \mathrm{~km})$; perhaps indicating the influence of local environment on functional richness (e.g., Heino, 2005), such as forest cover (e.g., leaf litter) or other land-use types that influence organism development or fitness (e.g., agricultural runoff). These findings have important potential implications for conservation measures, such that variation in functional richness, and subsequent ecosystem processes, could be positively affected by improving local environmental conditions, while variation in phylogenetic diversity may depend more on large-scale land management and network connectivity.

Spatial distance explained twice as much variation compared to environmental variation for two of the three different community diversity measures. Also, when explaining species richness, a large amount of the explained variation was assigned to the environment $\cap$ distance component, indicating that distance is an important factor for species richness as well. Distance to other communities, and thus likelihood of re-colonization after disturbances, not only explains the exchange of species among communities but also the potential for recolonization after disturbances. While effect size was not very large in absolute terms, models using topological distance generally explained more total variation compared to Euclidean distance, suggesting that topological (i.e., along-stream) distance better captures dispersal in macroinvertebrate communities than Euclidian (i.e., overland) dispersal. Our results support previous findings suggesting dispersal of EPT is generally characterized by the river network, either through downstream drift of larval stages (Elliott, 1971) or by aerial dispersal of adults along the river network, supporting the recommended use of topological distance measures to dispersal pathways of EPT (Altermatt, 2013). 
As with other empirical studies that utilize variance partitioning (e.g., Alahuhta \& Heino, 2013; Liu et al., 2013) we observed a relatively high amount of unexplained variation (77 to $83 \%$, Table C.1). We see two mutually, non-exclusive, explanations for the reduced amount of explained variation found in this, and other studies. First, some relevant environmental descriptors may not be included, or poorly resolved. We only used environmental factors commonly available from GIS databases so that they could be scaled to large areas. While similar environmental factors have been used in other studies (e.g., temperature and land-use type), these factors may only be indirect measures of resource availability (e.g., leaf litter in forests) or anthropogenic disturbances (e.g., agriculture). Thus, they may not resolve smallscale environmental differences or point-like effects, such as water treatment facility outflow or agricultural runoff. As the monitoring program (BDM Coordination Office, 2009; Stucki, 2010) is not collecting local-scale variables such as $\mathrm{pH}$, stream temperature or shading, we cannot exclude that the inclusion of such local-scale measures would improve our explanatory power. Our findings may support this explanation, to some degree, as environmental factors explained better the variation in species richness, compared to functional richness, which may reflect species-specific dependence on specific environmental factors. Second, much of the spatial differences in community diversity may be shaped by stochastic extinction or historic assembly effects, probably more so than generally acknowledged (Logue, Mouquet, Peter, \& Hillebrand, 2011; Vellend, 2010). If true, this indicates inherent limits in the predictability of the diversity of riverine invertebrate communities (see also Heino et al., 2015). For example, a large meta-analysis by Sundermann et al. (2011) found that re-colonization of EPT species strongly depends on the presence of these species at neighbouring sites ( $<5 \mathrm{~km}$ distance). Thus changes, especially declines, in metacommunity diversity may persist indefinitely before being compensated by dispersal. We are not aware of previous analyses of riverine macroinvertebrate diversity that included extensive temporal dynamics, which would be essential to reveal historic or stochastic processes. It is possible that such dynamics are the 
ultimate cause of, frequently observed, large differences in species richness among headwater riverine communities (Grant, Lowe, \& Fagan, 2007). Experimental results from dendritic networks support this perspective; showing that high among-community dissimilarity can occur in the absence of environmental differences (Carrara, Rinaldo, Giometto, \& Altermatt, 2014; Seymour \& Altermatt, 2014; Seymour, Fronhofer \& Seymour 2015)

Past studies have used subsets of explanatory variables, including environmental factors and distance, to describe patterns of metacommunity diversity. We found that the measure of the metacommunity diversity, as well as choice of distance and environmental descriptors, influenced the interpretations regarding the influence distance and environment have on riverine metacommunities. We conclude that analytical approaches that use more varied explanatory and response variables will give a better understanding of patterns and mechanistic processes in natural metacommunities.

\section{Acknowledgments}

The Swiss Federal Office for the Environment provided the BDM data. We thank the many people who conducted field and laboratory work within the biodiversity monitoring program, and N. Martinez who gave us access to the data. We thank L. Boumans, J. Gattolliat and S. Rutschmann for providing COI sequence data and R. Siber, for her assistance in acquiring GIS data. We thank K. Hövemeyer, P.R. Peres-Neto and three anonymous reviewers for their helpful and constructive comments. Funding was provided by the Swiss National Science Foundation, grants nr. 31003A_135622 and PP00P3_150698.

Appendix A. Supplementary data

Supplementary data associated with this article can be found, in the online version, at XXXXX 


\section{References}

Alahuhta, J., \& Heino, J. (2013). Spatial extent, regional specificity and metacommunity structuring in lake macrophytes. Journal of Biogeography, 40(8), 1572-1582. http://doi.org/10.1111/jbi.12089

Altermatt, F. (2013). Diversity in riverine metacommunities: a network perspective. Aquatic Ecology, 47(3), 365-377. http://doi.org/10.1007/s10452-013-9450-3

Altermatt, F., Alther, R., Fišer, C., Jokela, J., Konec, M., Küry, D., ... Westram, A. M. (2014). Diversity and Distribution of Freshwater Amphipod Species in Switzerland (Crustacea: Amphipoda). PLoS ONE, 9(10), e110328. Retrieved from http://dx.doi.org/10.1371\%2Fjournal.pone.0110328

Altermatt, F., Seymour, M., \& Martinez, N. (2013). River network properties shape $\alpha$ diversity and community similarity patterns of aquatic insect communities across major drainage basins. Journal of Biogeography, 40(12), 2249-2260. http://doi.org/10.1111/jbi.12178

Astorga, A., Oksanen, J., Luoto, M., Soininen, J., Virtanen, R., \& Muotka, T. (2012). Distance decay of similarity in freshwater communities: do macro- and microorganisms follow the same rules? Global Ecology and Biogeography, 21(3), 365-375. http://doi.org/10.1111/j.1466-8238.2011.00681.x

BAFU: Swiss Federal Office of the Environment. (2012). Einzugsgebietsgliederung Schweiz, Basisgeometrie. Bern, $\mathrm{CH}$.

BDM Coordination Office. (2009). The state of biodiversity in Switzerland: overview of the findings of biodiversity monitoring Switzerland (BDM) as of May 2009. State of the environment. Bern: Federal office for the environment.

Begert, M., Schlegel, T., \& Kirchhofer, W. (2005). Homogeneous temperature and precipitation series of Switzerland from 1864 to 2000. International Journal of Climatology, 25(1), 65-80. http://doi.org/10.1002/joc.1118

BFS: Swiss Federal Statistical Office. (2001). GEOSTAT: Benützerhandbuch. Bern, CH.

Blanchet, F. G., Legendre, P., Bergeron, J. A. C., \& He, F. (2014). Consensus RDA across dissimilarity coefficients for canonical ordination of community composition data. Ecological Monographs, 84(3), 491-511. http://doi.org/10.1890/13-0648.1

Blanchet, F. G., Legendre, P., \& Borcard, D. (2008a). Forward selection of explanatory variables. Ecology, 89(9), 2623-32. http://doi.org/10.1890/07-0986.1

Blanchet, F. G., Legendre, P., \& Borcard, D. (2008b). Modelling directional spatial processes in ecological data. Ecological Modelling, 215(4), 325-336.

http://doi.org/10.1016/j.ecolmodel.2008.04.001 
Borcard, D., Gillet, F., \& Legendre, P. (2011). Numerical Ecology with R. New York, US: Springer.

Borcard, D., Legendre, P., \& Drapeau, P. (1992). Partialling out the Spatial Component of Ecological Variation. Ecology, 73(3), 1045-1055. http://doi.org/10.2307/1940179

Cardoso, P., Rigal, F., Borges, P. A. V, \& Carvalho, J. C. (2014). A new frontier in biodiversity inventory: a proposal for estimators of phylogenetic and functional diversity. Methods in Ecology and Evolution, 5(5), 452-461. http://doi.org/10.1111/2041210X.12173

Carrara, F., Altermatt, F., Rodriguez-Iturbe, I., \& Rinaldo, A. (2012). Dendritic connectivity controls biodiversity patterns in experimental metacommunities. Proceedings of the National Academy of Sciences, 109(15), 5761-5766. http://doi.org/10.1073/pnas.1119651109

Carrara, F., Rinaldo, A., Giometto, A., \& Altermatt, F. (2014). Complex interaction of dendritic connectivity and hierarchical patch size on biodiversity in river-like landscapes. The American Naturalist, 183(1), 13-25. http://doi.org/10.1086/674009

Dray, S., Legendre, P., \& Peres-Neto, P. R. (2006). Spatial modelling: a comprehensive framework for principal coordinate analysis of neighbour matrices (PCNM). Ecological Modelling, 196(3-4), 483-493.

http://doi.org/http://dx.doi.org/10.1016/j.ecolmodel.2006.02.015

Elliott, J. M. (1971). The distances travelled by drifting invertebrates in a Lake District stream. Oecologia, 6(4), 350-379. http://doi.org/10.1007/bf00389109

Eme, D., Malard, F., Konecny-Dupré, L., Lefébure, T., \& Douady, C. J. (2013). Bayesian phylogeographic inferences reveal contrasting colonization dynamics among European groundwater isopods. Molecular Ecology, 22(22), 5685-5699. http://doi.org/10.1111/mec.12520

ESRI. (2011). ArcGIS Desktop: Release 10. Redlands, CA: Environmental Systems Research Institute.

Forest, F., Grenyer, R., Rouget, M., Davies, T. J., Cowling, R. M., Faith, D. P., ... Savolainen, V. (2007). Preserving the evolutionary potential of floras in biodiversity hotspots. Nature, 445(7129), 757-760. http://doi.org/10.1038/nature05587

Gilbert, B., \& Bennett, J. R. (2010). Partitioning variation in ecological communities: do the numbers add up? Journal of Applied Ecology, 47(5), 1071-1082. http://doi.org/10.1111/j.1365-2664.2010.01861.x

Grant, E. H. C., Lowe, W. H., \& Fagan, W. F. (2007). Living in the branches: population dynamics and ecological processes in dendritic networks. Ecology Letters, 10(2), 165175. http://doi.org/10.1111/j.1461-0248.2006.01007.x

Heino, J. (2005). Functional biodiversity of macroinvertebrate assemblages along major ecological gradients of boreal headwater streams. Freshwater Biology, 50(9), 15781587. http://doi.org/10.1111/j.1365-2427.2005.01418.x 
Heino, J., Melo, A. S., Bini, L. M., Altermatt, F., Al-Shami, S. A., Angeler, D. G., ... Cottenie, K. (2015). A comparative analysis reveals weak relationships between ecological factors and beta diversity of stream insect metacommunities at two spatial levels. Ecology and Evolution, 5(6), 1235-1248. http://doi.org/10.1002/ece3.1439

Holyoak, M., Leibold, M. A., \& Holt, R. D. (2005). Metacommunities. Spatial dynamics and ecological communities. Chicago: The University of Chicago Press.

Legendre, P., \& Cáceres, M. (2013). Beta diversity as the variance of community data: dissimilarity coefficients and partitioning. Ecology Letters, 16(8), 951-963. http://doi.org/10.1111/ele.12141

Legendre, P., \& Legendre, L. (2012). Numerical ecology (3rd ed.). Amsterdam: Elsevier Science BV.

Leibold, M. A., Economo, E. P., \& Peres-Neto, P. (2010). Metacommunity phylogenetics: separating the roles of environmental filters and historical biogeography. Ecology Letters, 13(10), 1290-1299. http://doi.org/10.1111/j.1461-0248.2010.01523.x

Leibold, M. A., Holyoak, M., Mouquet, N., Amarasekare, P., Chase, J. M., Hoopes, M. F., ... Gonzalez, A. (2004). The metacommunity concept: a framework for multi-scale community ecology. Ecology Letters, 7(7), 601-613. http://doi.org/10.1111/j.14610248.2004.00608.x

Liu, J., Soininen, J., Han, B.-P., \& Declerck, S. A. J. (2013). Effects of connectivity, dispersal directionality and functional traits on the metacommunity structure of river benthic diatoms. Journal of Biogeography, 40(12), 2238-2248. http://doi.org/10.1111/jbi.12160

Logue, J. B., Mouquet, N., Peter, H., \& Hillebrand, H. (2011). Empirical approaches to metacommunities: a review and comparison with theory. Trends in Ecology \& Evolution, 26(9), 482-491. http://doi.org/10.1016/j.tree.2011.04.009

Moog, O. (2002). Fauna Aquatica Austriaca (2nd ed.). Wien: Wasserwirtschaftskataster, Bundesministerium für Landund Forstwirtschaft, Umwelt und Wasserwirtschaft.

Muneepeerakul, R., Bertuzzo, E., Lynch, H. J., Fagan, W. F., Rinaldo, A., \& RodriguezIturbe, I. (2008). Neutral metacommunity models predict fish diversity patterns in Mississippi-Missouri basin. Nature, 453(7192), 220-222. http://doi.org/10.1038/nature06813

Münkemüller, T., Gallien, L., Lavergne, S., Renaud, J., Roquet, C., Abdulhak, S., ... Thuiller, W. (2014). Scale decisions can reverse conclusions on community assembly processes. Global Ecology and Biogeography, 620-632. http://doi.org/10.1111/geb.12137

Oksanen, J., Blanchet, F. G., Kindt, R., Legendre, P., Minchin, P. R., O’Hara, R. B., ... Wagner, H. (2009). vegan: Community Ecology Package. Retrieved from http://cran.rproject.org/package=vegan

Peres-Neto, P. R., Legendre, P., Dray, S., \& Borcard, D. (2006). Variation partitioning of species data matrices: estimation and comparison of fractions. Ecology, 87(10), 26142625. http://doi.org/10.1890/0012-9658(2006)87[2614:vposdm]2.0.co;2 
R Development Core Team. (2015). R: a languge and environment for statistical computing. Vienna: R Foundation for Statistical Computing. Retrieved from http://www.rproject.org

Rao, C. R. (1995). The use of Hellinger Distance in graphical displays of contingency table data. New Trends in Probability and Statistics, 3, 143-161.

Rodrigues, A. S. L., \& Gaston, K. J. (2002). Maximising phylogenetic diversity in the selection of networks of conservation areas. Biological Conservation, 105(1), 103-111. http://doi.org/http://dx.doi.org/10.1016/S0006-3207(01)00208-7

Rodriguez-Iturbe, I., \& Rinaldo, A. (1997). Fractal river networks: chance and selforganization. New York: Cambridge University Press.

Rosenzweig, M. L. (1995). Species Diversity in Space and Time (1st ed.). Cambridge, UK: Cambridge University Press.

Schierwater, B., Eitel, M., Jakob, W., Osigus, H.-J., Hadrys, H., Dellaporta, S. L., ... DeSalle, R. (2009). Concatenated Analysis Sheds Light on Early Metazoan Evolution and Fuels a Modern “Urmetazoon” Hypothesis. PLoS Biology, 7(1), e20. http://doi.org/10.1371/journal.pbio.1000020

Seymour, M., \& Altermatt, F. (2014). Active colonization dynamics and diversity patterns are influenced by dendritic network connectivity and species interactions. Ecology and Evolution, 4(8), 1243-1254. http://doi.org/10.1002/ece3.1020

Seymour, M., Fronhofer, E. A., \& Altermatt, F. (2015). Dendritic network structure and dispersal affect temporal dynamics of diversity and species persistence. Oikos, 124(7), 908-916. http://doi.org/10.1111/oik.02354

Seymour, M., Räsänen, K., Holderegger, R., \& Kristjánsson, B. K. (2013). Connectivity in a pond system influences migration and genetic structure in threespine stickleback. Ecology and Evolution, 3(3), 492-502. http://doi.org/10.1002/ece3.476

SFSO. (1998). Swiss land use in the European context: Integration of Swiss land use statistics with CORINE land cover. Neuchâtel, $\mathrm{CH}$ : Swiss Federal Statistical Office.

Smith, T. W., \& Lundholm, J. T. (2010). Variation partitioning as a tool to distinguish between niche and neutral processes. Ecography, 33(4), 648-655. http://doi.org/10.1111/j.1600-0587.2009.06105.x

Stucki, P. (2010). Methoden zur Untersuchung und Beurteilung der Fliessgewässer: Makrozoobenthos Stufe F. Bundesamt Für Umwelt, Bern. Umwelt-Vollzug, 1026, 61.

Sundermann, A., Stoll, S., \& Haase, P. (2011). River restoration success depends on the species pool of the immediate surroundings. Ecological Applications, 21(6), 1962-1971. http://doi.org/10.1890/10-0607.1

Thompson, J. D., Higgins, D. G., \& Gibson, T. J. (1994). CLUSTAL W: improving the sensitivity of progressive multiple sequence alignment through sequence weighting, 
position-specific gap penalties and weight matrix choice. Nucleic Acids Research, 22(22), 4673-4680. http://doi.org/10.1093/nar/22.22.4673

Turner, M. G., Gardner, R. H., \& O’Neill, R. V. (2001). Landscape ecology in theory and practice. New York, US: Springer.

Urban, M. C. (2004). Disturbance heterogeneity determines freshwater metacommunity structure. Ecology, 85(11), 2971-2978. http://doi.org/10.2307/3450537

Vannote, R. L., Minshall, G. W., Cummins, K. W., Sedell, J. R., \& Cushing, C. E. (1980). The River Continuum Concept. Canadian Journal of Fisheries and Aquatic Sciences, 37(1), 130-137. http://doi.org/10.1139/f80-017

Vaughan, I. P., Diamond, M., Gurnell, A. M., Hall, K. A., Jenkins, A., Milner, N. J., ... Ormerod, S. J. (2009). Integrating ecology with hydromorphology: a priority for river science and management. Aquatic Conservation: Marine and Freshwater Ecosystems, 19(1), 113-125. http://doi.org/10.1002/aqc.895

Vellend, M. (2010). Conceptual Synthesis in Community Ecology. The Quarterly Review of Biology, 85(2), 183-206. http://doi.org/10.1086/652373

Warton, D. I., Wright, S. T., \& Wang, Y. (2012). Distance-based multivariate analyses confound location and dispersion effects. Methods in Ecology and Evolution, 3(1), 89101. http://doi.org/10.1111/j.2041-210X.2011.00127.x

Weiher, E., \& Keddy, P. (1999). Ecological assembly rules: perspectives, advances, retreats. (E. Weiher \& P. Keddy, Eds.). Cambridge, UK: Cambridge University Press.

Weiss, M., Macher, J., Seefeldt, M., \& Leese, F. (2014). Molecular evidence for further overlooked species within the Gammarus fossarum complex (Crustacea: Amphipoda). Hydrobiologia, 721(1), 165-184. http://doi.org/10.1007/s10750-013-1658-7

Wiens, J. A. (1989). Spatial Scaling in Ecology. Functional Ecology, 3(4), 385. http://doi.org/10.2307/2389612 


\section{Figure legends}

Fig. 1. Schematic outline of the methodological approach used in this study. For each metacommunity diversity measure (species, functional and phylogenetic matrices), we calculated the amount of variation explained by the environment, distance and nonindependent environment $\cap$ distance. We calculated two estimates of distance, topological and Euclidean. Furthermore, we used six different grain sizes for the environmental measures (see also Appendix A: Fig. A.3). We conducted a separate variance partitioning analysis for each possible combination of the six environmental measures, the two geographic distance measures (Euclidean and topological) and the three diversity matrices, resulting in 36 separate analyses.

Fig. 2. Species richness (A), functional richness (B), and phylogenetic diversity (C) of mayflies, stoneflies and caddisflies. Each dot represents one of the 217 sampling sites within the Rhine drainage in our study area (Switzerland). Red colours represent high diversity values and blue colours representing low diversity values (see subplot legend for values).

Fig. 3. Pairwise comparisons of the different metacommunity diversity measures used in this study (species richness, functional richness and phylogenetic diversity). (A) Species versus functional richness, (B) phylogenetic diversity versus functional richness, (C) species richness versus phylogenetic diversity. We used generalized linear models (glm) to test the relationship between the different metacommunity diversity measures, and significant relationships are given by the fitted curve from the statistical model.

Fig. 4. Results of the variance partitioning analyses, showing the proportion of variance explained by environment, distance and environment-distance (divided into their respective panels) for the given metacommunity diversity measure and distance method. Each colour 
represents a metacommunity diversity measure $($ red $=$ species, green $=$ functional and blue $=$ phylogenetic). Upper panels depict analyses in which Euclidean distance was used to calculate distance and lower panels depict the use of topological distance. 
Fig. 1.

Diversity Environment + Distance + Environment $\cap$ Distance

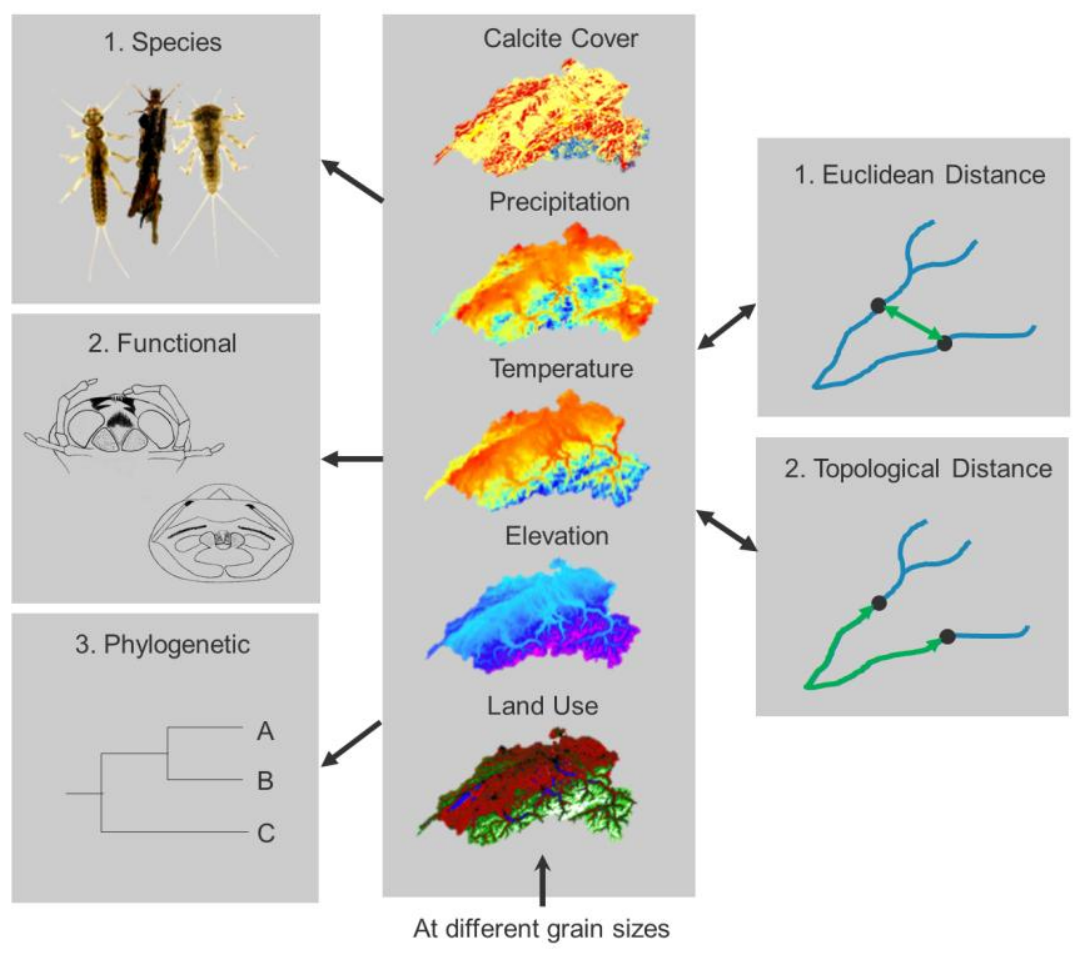


Fig. 2.
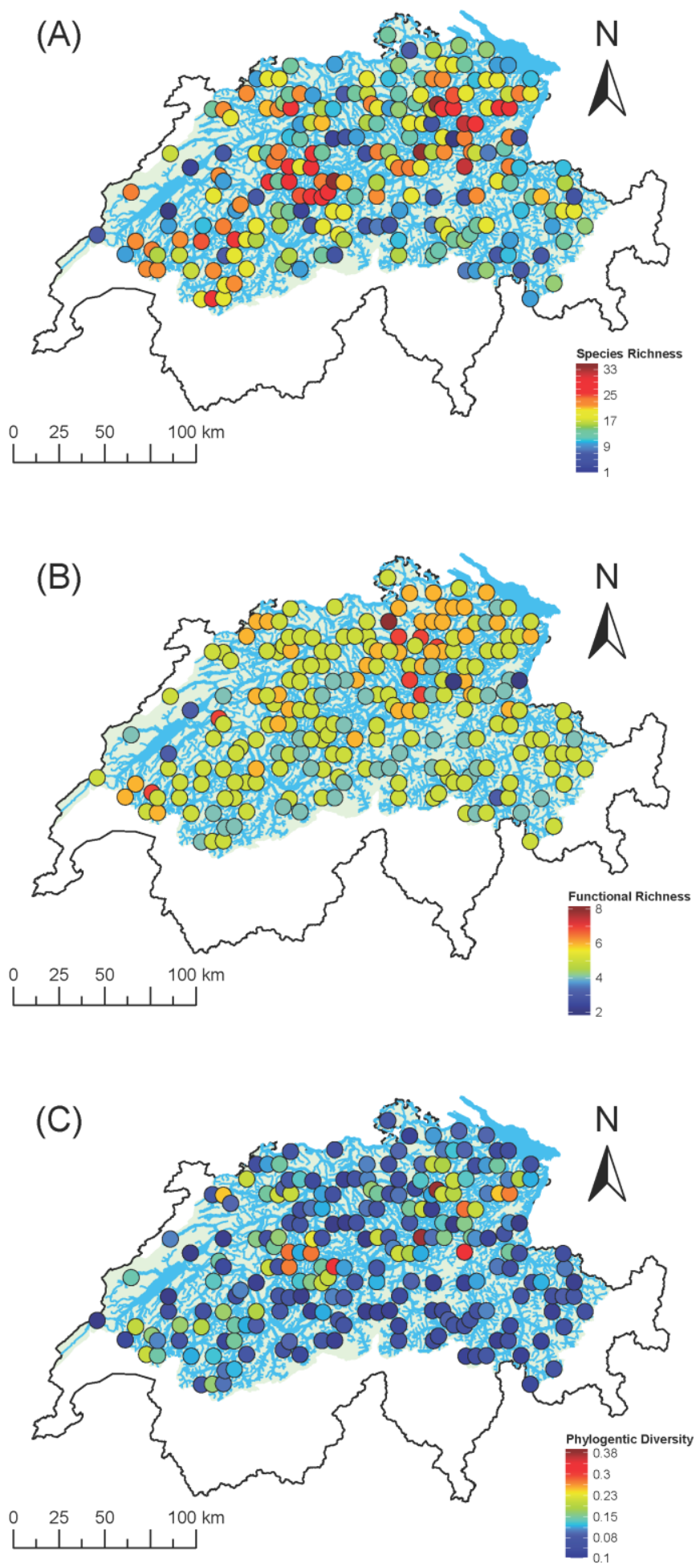
Fig. 3.
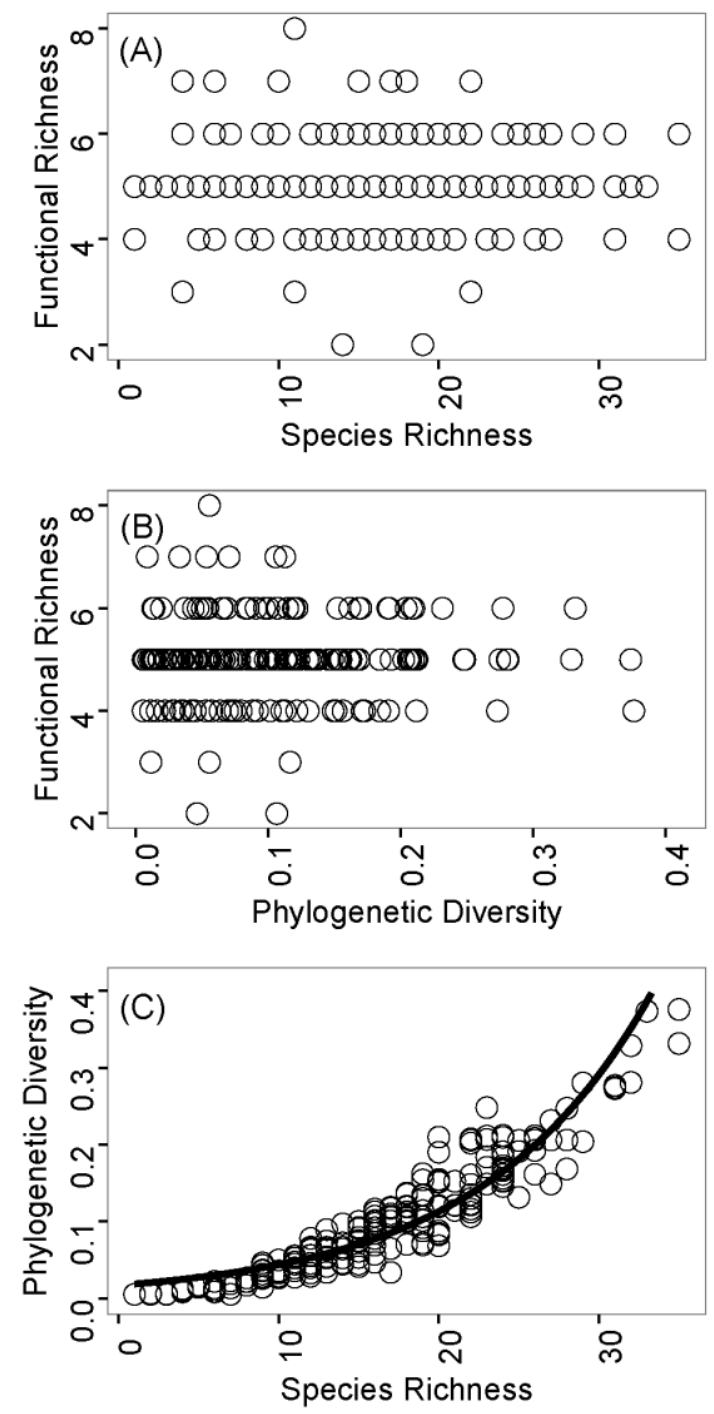
Fig. 4.

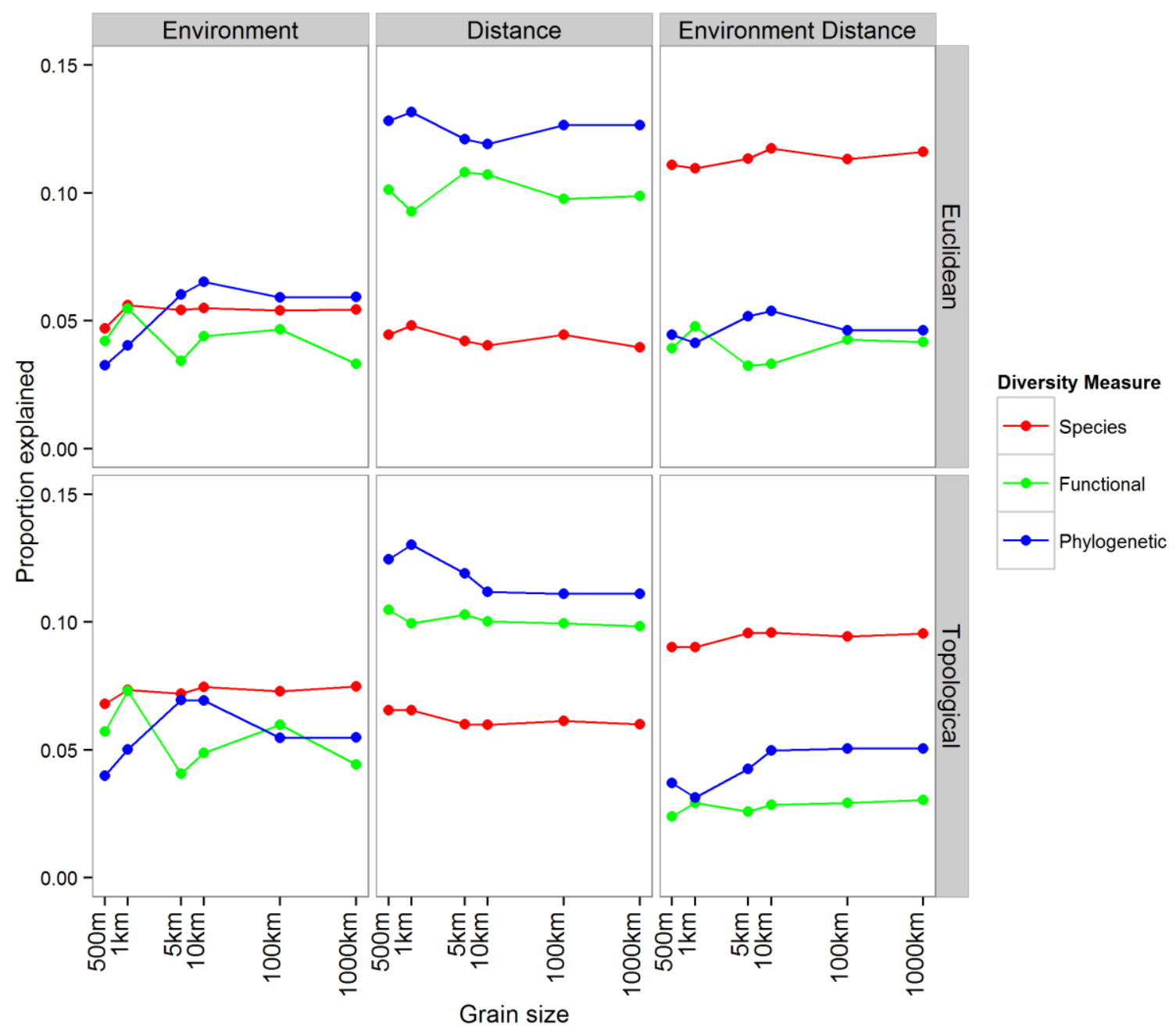

